\title{
A atualidade do conceito de semiformação e o renascimento da Bildung
}

\author{
Topicality of the semiformation concept and the rebirth of Bildung
}

\author{
Vânia Gomes Zuin* \\ Antônio Álvaro Soares Zuin **
}

\section{Resumo}

Theodor W. Adorno publicou o ensaio "Teoria da semiformação" (Theorie der Halbbildung) em 1959. A partir da publicação deste texto, observou-se sua relevância, sobretudo para que se pudesse compreender a maneira como a indústria cultural determinava a produção de prejuízos significativos no processo formativo. Desde então, a conquista do espírito feita pelo caráter fetichista dos produtos da indústria cultural, sendo esta uma das definições de Adorno sobre o conceito de Halbbildung, impulsionou a realização de muitas pesquisas sobre os danos decorrentes desta conquista na formação. Porém, investigar as atuais características do processo semiformativo não resulta na aplicação direta dos conceitos propostos por Adorno no final da década de 1950. Sendo assim, é preciso que tais conceitos sejam revitalizados por meio da análise das atuais mediações históricas. Seguindo essa linha de raciocínio, o principal objetivo deste artigo é argumentar que a reflexão crítica sobre o modo como a semiformação se renova, na atual sociedade da chamada cultura digital, torna-se fundamental para que se possam elaborar considerações sobre o renascimento da formação (Bildung).

Palavras-chave: Cultura digital. Formação. Indústria cultural. Teoria da semiformação. Theodor W. Adorno.

\section{Abstract}

Theodor W. Adorno published the essay: Theory of semiformation (Theorie der Halbbildung) in 1959. From this publication, its relevance was observed especially in order to understand the way in which the cultural industry determined the production of damages in the formation process. Since then, the conquest of the spirit made by the fetishistic character of the cultural industry products, being this one of Adorno's definitions on the concept of Halbbildung, impelled the accomplishment of many investigations on the damages resulting from this conquest in the formation. However, investigating the current characteristics of the semiformation process does not result in the direct application of the concepts engendered by Adorno in the late 1950s. Therefore, it is necessary that this concept can be revitalized through the analysis of the current historical mediations. In this way,

Recebido em: 08/03/2017 - Aprovado em: 15/07/2017

http://dx.doi.org/10.5335/rep.v24i3.7757

Doutora em Ciências e em Educação pela USP, com estágio doutoral na Universitá degli Studi di Torino, Itália, e com pós-doutorado em Química na USP, pelo Helmholtz-Zentrum für Umweltforschung, Alemanha, com apoio da Fundação Alexander von Humboldt (AvH), e pelo Green Chemistry Centre of Excellence, da University of York, Inglaterra (GCCE-UoY). Professora associada do Departamento de Química da Universidade Federal de São Carlos, credenciada nos Programas de Pós-Graduação em Química e Educação e professora convidada do GCCE-UoY, Inglaterra. E-mail: vaniaz@ufscar.br

** Doutor em Educação pela Universidade Estadual de Campinas (1998), com estágio doutoral na Universidade Johann Wolfgang von Goethe, Alemanha (bolsa do DAAD), e com pós-doutorados em Filosofia da Educação na Universidade de Leipzig, Alemanha, com bolsas Capes e Fapesp, e em Psicologia da Educação na Universidade de York, Inglaterra, com bolsas Fapesp e Capes. Professor titular do Departamento de Educação e do Programa de Pós-Graduação em Educação da Universidade Federal de São Carlos. E-mail: dazu@ufscar.br 
the main objective of this article is to argue that the critical reflection on the way in which the semiformation is renewed in the current society of the so-called digital culture becomes fundamental in order to elaborate considerations on the rebirth of the formation concept (Bildung).

Keywords: Digital Culture. Formation. Culture Industry. Theory of semiformation. Theodor W. Adorno.

\section{Introdução}

Em termos quantitativos, não se observa, na vasta produção de Theodor W. Adorno, a existência de muitos textos cujas temáticas sejam relacionadas diretamente à educação. De fato, se for possível comparar a quantidade de seus textos vinculados à filosofia, à sociologia e, principalmente, à crítica musical, as produções de caráter eminentemente educacional são como que empalidecidas diante do poder de análise e da quantidade de obras vinculadas à exposição e ao debate de questões filosóficas, sociológicas e musicais. Porém, tal palidez de ordem quantitativa rapidamente contrasta com a qualidade da análise de Adorno sobre temas relacionados direta ou indiretamente aos fenômenos educacionais. Certamente, este é o caso de seu texto intitulado: "Teoria da semiformação" (Theorie der Halbbildung).

Publicado no ano de 1959, a Theorie der Halbbildung foi traduzido para a língua portuguesa por Newton Ramos-de-Oliveira e publicado pela primeira vez em 1996, com o título: "Teoria da semicultura" (ADORNO, 1996), na revista $E d u$ cação \& Sociedade. Já no ano de 2010, o professor Ramos-de-Oliveira publicou uma versão desse texto no livro: Teoria crítica e inconformismo: novas perspectivas de pesquisa (PUCCI; ZUIN; LASTÓRIA, 2010), com o título: "Teoria da semiformação" (ADORNO, 2010). É interessante destacar a opção de mudança de tradução do conceito de Halbbildung de semicultura para semiformação. Embora não seja de todo equivocada a tradução de Halbbildung por semicultura, a escolha do termo semiformação parece ser mais adequada, sobretudo pela ênfase observada nos prejuízos na dimensão subjetiva, decorrentes da sociedade na qual a indústria cultural se torna hegemônica.

De todo modo, "Teoria da semiformação" se tornou um texto decisivo para a produção de vários estudos, inclusive de caráter empírico, realizados por pesquisadores brasileiros e estrangeiros. A conquista do espírito feita pelo caráter fetichista dos produtos da indústria cultural, sendo esta uma das definições de Adorno sobre o conceito de Halbbildung, impulsionou a realização da muitas pesquisas sobre os danos decorrentes desta conquista no processo formativo. De fato, é possível observar os desdobramentos do modo como a semiformação se faz presente na forma como a chamada educação a distância é atualmente promovida pelas instituições universitárias (PUCCI, 2012; ZUIN; BORGONOVE, 2016); no modo como ideolo- 
gicamente são apresentados os rótulos verdes de produtos propagandeados com a preocupação de se fomentar práticas ambientais sustentáveis (ZUIN; ZUIN, 2012); ou nos trotes universitários que se fundamentam em práticas de "integração" universitária de caráter sadomasoquista (ZUIN, 2012); entre outras pesquisas.

Em tais produções, as considerações de Adorno a respeito da forma como a indústria cultural promovia e disseminava tais danos foram, em muitas ocasiões, repensadas de acordo com as mediações históricas dos tempos e espaços em que tais mediações foram produzidas. Com efeito, investigar as características do processo semiformativo não resulta na aplicação direta dos conceitos engendrados por Adorno no final da década de 1950. Daí a importância de que o conceito de semiformação seja revitalizado por meio da análise das atuais mediações históricas. Seguindo esta linha de raciocínio, o principal objetivo deste artigo é argumentar que a reflexão crítica sobre o modo como a semiformação se renova na atual sociedade da chamada cultura digital torna-se fundamental para que se possa elaborar considerações sobre o renascimento da formação (Bildung). Para tanto, primeiramente, é preciso refletir sobre as principais características do conceito de semiformação, tal como foi originariamente elaborado por Adorno.

\section{A teoria da semiformação e a indústria cultural da década de 1950}

A leitura do primeiro parágrafo da "Teoria da semiformação" pode engendrar certo desalento quanto à crença no poder das reformas pedagógicas em solucionar os problemas referentes ao que Adorno denominou como o colapso da formação (Bildung). Porém, a afirmação do pensador frankfurtiano conserva justamente o mérito de desvelar o véu ideológico de que bastaria serem elaboradas determinadas regras para que o colapso do processo formativo fosse dirimido. Na verdade, ao enfatizar as características do sonho de tal processo formativo, Adorno concomitantemente identificou as mediações histórias que o danificaram da seguinte forma:

A formação devia ser aquela que dissesse respeito - de uma maneira pura como seu próprio espírito - ao indivíduo livre e radicado em sua própria consciência, ainda que não tivesse deixado de atuar na sociedade e sublimasse seus impulsos. A formação era tida como condição implícita a uma sociedade autônoma: quanto mais lúcido o singular, mais lúcido o todo. Contraditoriamente, no entanto, sua relação com uma práxis ulterior apresentou-se como uma degradação a algo heterônomo, como percepção de vantagens de uma irresolvida bellum omnium contra omnes (ADORNO, 2010, p. 13).

Diante do contexto de expansão das relações capitalistas de produção, no qual se afirmava cada vez mais o estado da guerra de todos contra todos, esfacelavam-se as condições socioculturais e políticas que forneceriam o lastro necessário para o 
processo formativo do indivíduo livre e radicado em sua própria consciência, mesmo que tivesse que sublimar seus impulsos diante do cumprimento das regras estipuladas nos contratos sociais. É interessante notar a forma como Adorno utiliza o conceito psicanalítico de sublimação como condição fulcral para que o indivíduo pudesse kantianamente sair do seu estado de menoridade, de indivíduo tutelado.

Ao aprender a adiar a realização de seus desejos para que fossem satisfeitos em situações mais favoráveis ou, então, a proceder desta forma em função do objetivo de antecipar as consequências decorrentes de sua satisfação pessoal em outras pessoas, o indivíduo portador da Bildung seria capaz de se sensibilizar a ponto de perceber que os conceitos de ética e de responsabilidade seriam palavras absolutamente vazias, caso não houvesse o esforço necessário de se exercer uma práxis que não as contrariasse.

É por isso que ser identificado, e se identificar, como um indivíduo formado não pode ser reduzido exclusivamente ao conhecimento de determinadas línguas ou à leitura de vários livros, por exemplo. Ou seja, o conhecimento de uma miríade de informações relativas às mais variadas áreas pode ser feito de forma absolutamente instrumentalizada, a ponto de uma pessoa ser identificada como alguém que é culto por justamente saber o que o próprio Adorno escreveu sobre o preconceito e continuar a reproduzir comportamentos preconceituosos nas situações do cotidiano. A propósito, Adorno ressalta a observação de Max Frisch de que, em situações-limite, tal como a do nazismo, muitas pessoas que se dedicavam apaixonadamente à compreensão dos chamados bens culturais não hesitaram em se entregar totalmente à "prática assassina do nacional-socialismo" (ADORNO, 2010, p. 10).

Esta fratura entre o conceito e a práxis instrumentalizada não pode ser resolvida por meio das reformas pedagógicas, por mais necessárias que elas sejam, pois tal fratura é produto de um determinado espírito objetivo de um tempo, ou melhor, de um processo de industrialização que determina a mercantilização ubíqua, inclusive das produções culturais, as quais, não por acaso, passam a ser identificadas como bens, de tal maneira que, "na linguagem da filosofia pura, a cultura converteu-se, satisfeita de si mesma, em um valor" (ADORNO, 2010, p. 10, grifo do autor). Justamente, a conversão praticamente absoluta da cultura em um valor remete o raciocínio à análise do conceito de indústria cultural. Certamente um dos principais conceitos elaborados por Adorno e Horkheimer, o nome indústria cultural tornou-se objeto de análise dos pensadores frankfurtianos no livro Dialética do esclarecimento: fragmentos filosóficos (ADORNO; HORKHEIMER, 1986), sobretudo no capítulo "A indústria cultural: o esclarecimento como mistificação das massas".

É interessante destacar as palavras: mistificação das massas, uma vez que o significado do termo Massenbetrug (HORKHEIMER; ADORNO, 1972, p. 146) é 
o de mistificação no sentido de engodo. Ou seja, no contexto histórico da hegemonia da indústria cultural, ocorre a conversão do esclarecimento (Aufklärung) como engodo das massas. Dito em outros termos: o acesso massificado aos "produtos culturais" não significaria necessariamente que os indivíduos se tornariam livres e radicados em suas próprias consciências. Ao contrário, o consumo desenfreado de tais produtos tenderia a fomentar a disseminação dos pensamentos padronizados, das práticas preconceituosas delirantes e de uma consciência fragmentada praticamente incapaz de relacionar historicamente o passado com o presente, para que se pudesse pensar um futuro diferente.

No texto: Résumé über Kulturindustrie, traduzido como "A indústria cultural", que se baseou em conferências radiofônicas proferidas na Alemanha em 1962, Adorno explicitou a dialética da relação entre indústria e cultura no apogeu do capitalismo monopolista da seguinte forma:

Enquanto o processo de produção no setor central da indústria cultural - o filme - se aproxima de procedimentos técnicos através da avançada divisão do trabalho, da introdução de máquinas e da separação dos trabalhadores dos meios de produção (essa separação manifesta-se no eterno conflito entre os artistas ocupados na indústria cultural e os potentados desta), conservam-se também formas de produção individual. Cada produto apresenta-se como individual; a individualidade mesma contribui para o fortalecimento da ideologia, na medida em que se desperta a ilusão de que o que é coisificado e mediatizado é um refúgio do imediatismo e da vida (ADORNO, 1986, p. 94).

Contudo, não se pode deduzir que tal reificação das consciências ocorre numa relação de causa e efeito, de tal maneira que fosse possível obter somente esse tipo de resultado. Além do fato de que há produtos da própria indústria cultural cuja relação entre forma e conteúdo conflitua com a lógica de massificação e padronização da mercantilização de tais produtos, a suposta passividade de seus consumidores é ativamente vivenciada. Ou seja, tais consumidores precisam vivenciar ativamente sua própria passividade, pois, muitas vezes, são cônscios das mentiras de que basta consumir determinado produto para que todos seus desejos possam ser imediatamente satisfeitos. Porém, mesmo que tenham consciência desse fato, continuam consumindo-os, uma vez que, se o prazer final não pode mesmo ser obtido, esta frustração é compensada pelo consumo maciço de produtos que proporcionam a fruição de pré-prazeres contínuos. Não por acaso, Adorno e Horkheimer asseveraram que:

A Indústria cultural não sublima, mas reprime. Expondo repetidamente o objeto do desejo, o busto no suéter e o torso nu do herói esportivo, ela apenas excita o prazer preliminar não sublimado que o hábito da renúncia há muito mutilou e reduziu ao masoquismo. Não há nenhuma situação erótica que não junte à alusão e à excitação a indicação precisa de que jamais se deve chegar a esse ponto [...]. A produção em série do objeto sexual produz automaticamente seu recalcamento (ADORNO; HORKHEIMER, 1986, p. 131). 
A excitação do prazer preliminar, do pré-prazer, feita pela indústria cultural, converte-o numa espécie de sucedâneo do prazer, de modo que a sensação de desconforto, decorrente dessa conversão, é ilusoriamente compensada pela busca frenética de produtos que anunciam finalmente o gozo da sensação plenamente prazerosa. Sendo assim, não foi fortuita a comparação de Adorno e Horkheimer entre o ritual da indústria cultural e o de Tântalo. Como se sabe, ao ser punido pelos deuses por haver roubado manjares e ter-lhes dado aos humanos, Tântalo foi punido da seguinte maneira: quando queria beber água e dela se aproximava, imediatamente ela se afastava; quando sentia fome e tentava apanhar frutos, os ramos das árvores imediatamente se retraíam.

De forma semelhante, os Tântalos que consomem os produtos da indústria cultural também têm a sensação de que, muito em função do desenvolvimento tecnológico, finalmente, tais produtos lhes propiciarão a sensação do prazer absoluta, mas eles lhes escapam tão logo tentam apanhá-los. Evidentemente, diante deste quadro, recrudescem os prejuízos no processo formativo de tais indivíduos, a ponto de se produzir o que Adorno denominou como semiformação, a saber, a "conquista do espírito pelo caráter fetichista da mercadoria” dita cultural (ADORNO, 2010, p. 25).

Assim, o indivíduo semiformado, que afirma não ter tempo para poder aprofundar seu conhecimento sobre determinado assunto, orgulha-se de si próprio quando obtém o reconhecimento de outros indivíduos semiformados que agem da mesma forma e se identificam como partícipes do mesmo team. É por isso que Adorno afirma que este tipo de narcisismo coletivo

[...] faz com que as pessoas compensem a consciência de sua impotência social - consciência que penetra até em suas constelações instintivas individuais - e, ao mesmo tempo, atenuem a sensação de culpa por não serem nem fazerem o que, em seu próprio conceito, deveriam ser e fazer (ADORNO, 2010, p. 32).

$\mathrm{Na}$ verdade, os indivíduos semiformados, muitas vezes, têm consciência de sua própria impotência e do quão distante se encontram daquela formação afeita à possibilidade de que eles e elas se sensibilizem a respeito da necessidade de se arrefecer as barreiras entre o conceito aprendido e sua aplicação prática. Mas o prazer obtido pelos indivíduos semiformados diante do narcisismo que praticam entre si como que neutraliza a sensação de culpa "por não serem nem fazerem o que, em seu próprio conceito, deveriam ser e fazer" (ADORNO, 2010, p. 32). Esta mesma sensação de culpa poderia, em determinadas circunstâncias, nutrir o sentimento de vergonha que, por ser um sentimento de ordem moral, impulsionaria o indivíduo a realizar a autocrítica necessária para que pudesse refletir sobre o prazer obtido, por meio do exercício do pensamento estereotipado e do comportamento preconceituoso. Entretanto, como isso dificilmente ocorre, os fundamentos 
da experiência formativa são abalados na medida em que a semiformação impõe sua supremacia:

A experiência - a continuidade da consciência em que perdura o ainda não existente e em que o exercício e a associação fundamentam uma tradição no indivíduo - fica substituída por um estado informativo pontual, desconectado, intercambiável e efêmero, e que se sabe que ficará borrado no próximo instante por outras informações. Em lugar do temps durée, conexão de um viver em si relativamente uníssono que desemboca no julgamento, coloca-se um "É assim" sem julgamento, algo parecido à fala dos viajantes que, do trem, dão nomes a todos os lugares pelos quais passam como um raio, a fábrica de rodas ou de cimento, o novo quartel; sempre prontos para dar respostas inconsequentes a qualquer pergunta. A semiformação é uma fraqueza em relação ao tempo, à memória, única mediação capaz de fazer na consciência aquela síntese da experiência que caracterizou a formação cultural em outros tempos (ADORNO, 2010, p. 33).

O ainda não existente, ou seja, o futuro, que se acena como possibilidade derivada da forma como as mediações históricas do passado e do presente são relacionadas entre si, é vislumbrado pela consciência do indivíduo cujo processo formativo o sensibilizou a refletir sobre os nexos espaço-temporais entre passado, presente e futuro. Ora, esta mesma experiência formativa é substituída por um "[...] estado informativo pontual, desconectado, intercambiável e efêmero, e que se sabe que ficará borrado no próximo instante por outras informações" (ADORNO, 2010, p. 33). Este é o estado da semiformação: um estado desconectado, intercambiável e efêmero, que será facilmente esquecido tão logo algum objetivo seja cumprido, tal como no caso dos estudantes brasileiros de ensino médio que são treinados a despejar informações nos exames vestibulares, informações estas que serão majoritariamente esquecidas assim que forem aprovados e começarem a frequentar a vida universitária. Mas, se a semiformação pode ser identificada como uma fraqueza em relação à memória, então ela não mais existiria na sociedade cuja digitalização das informações, e da própria vida, não permite mais que haja quaisquer tipos de esquecimento? Para que uma questão como esta possa ser respondida, é preciso refletir sobre o modo como a Halbbildung é revitalizada na sociedade da chamada cultura digital, sendo que este fato também implica na possibilidade de renascimento da Bildung.

\section{A semiformação na cultura digital e a Bildung renascida}

Uma das principais obras cuja leitura possibilita refletir sobre a atualidade da indústria cultural, bem como sobre os prejuízos resultantes no processo formativo, é o livro Sociedade excitada: filosofia da sensação, de Christoph Türcke. Lançado na Alemanha em 2002 e publicado no Brasil em 2010, essa obra tornou-se referên- 
cia importante para todos os pesquisadores interessados no modo como, na sociedade da cultura digital, desenvolve-se o chamado vício de consumo de estímulos audiovisuais, fato este que promove modificações profundas tanto na elaboração de representações mentais duradouras quanto na percepção sensório-motora que fornece o lastro necessário para o desenvolvimento de tais representações.

É interessante enfatizar a forma como Türcke consubstancia o vício de consumo dos atuais choques audiovisuais com a consolidação de uma nova ontologia: a de que ser significa ser percebido por meio da compulsão, para emitir a própria imagem e comentários, sobretudo por meio do uso incessante das redes sociais. Para Türcke:

da mesma forma como a força integradora do mercado nunca foi somente econômica, nunca decidindo apenas a respeito do trabalho ou desemprego, mas sempre também sobre aceitação ou rejeição, em certo sentido, então, sobre o ser ou não ser, assim também essa pressão ontológica sob condições de uma compulsão generalizada para a emissão adquiriu uma forma estética. Dito inversamente: a estética ganhou um peso ontológico como nunca tivera. Isso também faz parte do esse est percipi. Essa frase expressa não apenas a ontologia paradoxal da era microeletrônica, que uma existência sem presença eletrônica é um aqui e agora sem um "aî", um não ser em um corpo vivo; também aponta para o que isso significa para a fisiologia da percepção (TÜRCKE, 2010, p. 65).

Esse est percipi, ou seja, ser significa ser percebido. Não deixa de ser irônica a forma como esta frase de George Berkeley, filósofo irlandês do século XVIII, é midiática e eletronicamente renovada na atual sociedade da cultura digital. Se Berkeley associou a existência dos objetos e das pessoas à condição de serem percebidos, sendo esta uma capacidade advinda das graças de Deus, já no capitalismo transnacional do século XXI, esta mesma constatação adquire um peso ontológico inaudito, na medida em que, se indivíduo não se emitir midiatica e eletronicamente e, portanto, for percebido, é como se fosse uma não existência viva.

Mas a consolidação desta nova ontologia não pode ser exclusivamente relacionada aos desejos e às idiossincrasias de um indivíduo, pois, nesta compulsão em emitir-se, principalmente por meio das redes sociais, encontra-se mediado o espírito objetivo de um tempo no qual as telas se tornam onipresentes tanto nas relações de trabalho quanto nas estabelecidas durante o chamado tempo livre, as quais se assemelham cada vez mais.

Adorno e Horkheimer já haviam observado que a diversão significava "o prolongamento do trabalho" (1986, p. 128) no capitalismo da indústria cultural de meados do século XX. Isso porque fora do trabalho o indivíduo semiformado sentia a necessidade de se adequar à mesma lógica de pensamentos e operações padronizados que exercia nas fábricas e nos escritórios, por exemplo. Seguindo esta linha de raciocínio, haveria uma relação de correspondência entre a execução de operações 
padronizadas, as quais seriam produtos das relações mentais de causa e efeito de tais indivíduos, e a presença desta mesma lógica nos filmes cujos espectadores já sabiam exatamente ao que iriam assistir e o que iriam consumir audiovisualmente durante as duas horas de projeção.

Porém, na sociedade da cultura digital, fruto da denominada revolução microeletrônica, é a esfera da produção se subsome à do chamado tempo livre, por meio do processo de ubiquidade da tela, de modo que:

A tela, o grande recheio do tempo livre, penetrou profundamente, por meio do computador, no mundo do trabalho: a coordenação de processos inteiros de produção e administração perpassa por ela, de tal modo que se apresenta como instrumento do ensino do futuro (TÜRCKE, 2010, p. 267).

A universalização da tela feita por meio do computador e suas mais variadas formas - notebooks, tablets, computadores de mesa, entre outras - fomentou a produção de consequências tanto físicas quanto psicológicas que não foram identificadas em toda a sua plenitude, haja vista o fato de que estão sendo ainda vivenciadas. Mas uma delas se destaca diante do fluxo e do consumo contínuos de imagens e sons que se digladiam com o escopo de capturar a atenção de seus consumidores: o vício de consumo dos choques audiovisuais. Se, há alguns anos atrás, as pessoas tinham contato com os choques audiovisuais apenas uma vez por semana, quando frequentavam as salas de cinema, e se tal experiência mudou radicalmente com a massificação da televisão, uma vez que o contato com as telas tornou-se diário, já na sociedade na cultura digital, o consumo de tais choques se torna ininterrupto. De acordo com Türcke:

Em seu encanto, o tiro ótico cativa de forma irresistível, pois através de uma repetição permanente ele orienta, de modo gradativo, todo o sensório em si, tanto fisiológica quanto esteticamente, até se tornar imprescindível, como se fosse uma injeção que o organismo precisa diariamente. E porque toda a injeção também anestesia, torna-se uma consequência inevitável a exigência de doses mais poderosas (2010, p. 266).

São muitas as sensações prazerosas derivadas do consumo incessante de choques audiovisuais que assumem a forma do tiro ótico. Fisiologicamente, as sensações de prazer advindas desse tipo de consumo podem ser observadas nos olhares embasbacados das crianças, que simplesmente param de fazer qualquer coisa caso lhes sejam apresentadas as telas cujas imagens multicoloridas cintilam intensamente, ao mesmo tempo em que mudam numa velocidade estonteante. Esteticamente, o fluxo contínuo de tais imagens chocantes também fornece diretrizes de percepção e ação, de tal modo que elas como que pensam cada vez mais pelos seus consumidores, não o contrário, ocorrendo uma espécie de canibalismo da esfera simbólica, de acordo com a expressão de Lash e Lury (2007). Nesse sentido, a sig- 
nificação deixa de ser hermenêutica para se tornar cada vez mais operacional, uma vez que o significado dificilmente se consubstancia com a interpretação, "mas sim com o próprio fazer, com o impacto" (LASH; LURY, 2007, p. 12).

$\mathrm{Na}$ cultura na qual se arrefece a capacidade de simbolização, também a concentração se transforma de modo inaudito. Para Türcke, é na sociedade da cultura digital que se desenvolve o fenômeno da distração concentrada, que foi definido da seguinte forma: "De modo fulminante, o choque concentra a atenção num ponto, para poder triturar esta concentração através de incontáveis repetições. $O$ meio de concentração é, propriamente, o meio de decomposição" (TÜRCKE, 2010, p. 266), de tal modo que "[...] o choque fílmico e a atividade de trabalho se tornam um só. O imperativo categórico 'olhe para cá' se transforma, ao mesmo tempo, em necessidade econômica" (TÜRCKE, 2010, p. 267). Frente à oferta contínua de choques audiovisuais, que conseguem capturar por instantes a atenção dos que os consomem, dificilmente há o tempo necessário para que se reflita sobre o que está sendo consumido, haja vista que novos links "clamam" para que sejam imediatamente acessados. É nesse contexto que o meio de concentração da atenção produz sua própria decomposição. Pois, assim que é focada num choque audiovisual, a atenção se despedaça na forma de distrações, que se sucedem no ritmo contínuo e alucinante das trocas de imagens e sons.

Türcke enfatizou as características do tiro ótico em 2002, ano de publicação da Erregte Gesellschat: Philosophie der Sensation na Alemanha. Todavia, mesmo naquela sociedade, na qual a tela dos computadores já se universalizava para praticamente todos os espaços das relações de trabalho e do tempo livre, havia ainda situações de descanso. É interessante observar que a chamada tela de descanso dos computadores, que eram automaticamente acionadas quando não se fazia uso de tais máquinas por alguns minutos, proporcionava, na verdade, o descanso do indivíduo que, por alguns instantes, não consumia os choques audiovisuais. Mas tal situação muda de forma decisiva com a disseminação de um gadget eletrônico: o aparelho celular.

Desde o surgimento e da posterior propagação dos celulares, no final da década de 1990, praticamente, não há mais a possibilidade de descanso fisiológico e estético, uma vez que as pessoas consomem os choques audiovisuais em quaisquer espaços e tempos (ZUIN; ZUIN, 2016). Assim, o vício decorrente do consumo de tais choques adquire outra dimensão psicossocial. A portabilidade dos computadores de bolso - que permitem ao usuário se comunicar on-line por meio do uso das redes sociais, ser localizado e localizar qualquer espaço, acessar quaisquer informações, assistir a vídeos e programas de TV, acessar redes sociais, entre outras funções faz com que seja insuportável não estar com tal aparelho, o que gera uma sensação de angústia típica do estado dos viciados que são privados de drogas e desenvolvem a síndrome de abstinência. 
Na sociedade da cultura do aparelho celular (GOGGIN, 2007), o vício de consumo dos choques audiovisuais, produzido pelo uso de celulares, adquire tamanho vulto que faz as pessoas que os esquecem, por quaisquer motivos, em suas casas retornarem imediatamente para buscá-los, pois ficar sem eles significaria o mesmo que retirar uma parte do próprio corpo. Assim, a ontologia do ser significar ser midiatica e eletronicamente percebido finalmente se torna ubíqua, de modo que não estar disponível on-line o tempo todo pode acarretar tanto a perda do próprio emprego quanto o desapontamento da pessoa que não recebeu o retorno imediato de uma mensagem de WhatsApp ou um feedback (como um like) no Facebook, em qualquer lugar e momento.

Evidentemente, a sensação de angústia de não se estar on-line pode ser observada nos sujeitos que estão envolvidos tanto nas relações de trabalho quanto nas relações do chamado tempo livre, cujas fronteiras se esfacelam cada vez mais, do mesmo modo que os limites entre as esferas pública e privada também são cotidianamente destroçados. São cada vez mais comuns os casos das pessoas que simplesmente se conectam por meio de seus celulares independentemente do lugar e da situação que estejam envolvidas. Tanto alunos quanto professores acessam suas contas nas redes sociais por meio de tais aparelhos, mesmo durante as aulas, ministradas desde o ensino fundamental até o superior, por exemplo. Justamente, a impossibilidade cada vez mais frequente de se apartar de tais aparelhos e de todas as suas funções está produzindo transformações estruturais tanto em relação à produção e à disseminação das informações quanto na produção da memória, principalmente a respeito da maneira como tais informações são lembradas ou esquecidas.

Atualmente, torna-se cada vez mais difícil, para não dizer insuportável, fixar a concentração em determinada informação durante apenas algumas dezenas de segundos. O ritmo alucinante das distrações que continuamente se alternam, na medida em que nossos olhares são atraídos por estímulos audiovisuais expostos por telas omnipresentes, parece estar fazendo com que a própria capacidade de concentração seja radicalmente transformada, de tal modo que a dispersão torna-se parte de sua constituição. Ou seja: as incontáveis distrações produzidas cotidianamente, que concentram a atenção no choque audiovisual para, logo em seguida, triturá-la, estão, ao que tudo indica, fomentando uma transformação decisiva na própria capacidade de concentração, que se metamorfoseia na chamada concentração dispersa. Diante do atual bombardeamento dos choques audiovisuais, os quais são consumidos continuamente pelo uso dos aparelhos celulares, a dispersão não se torna uma espécie de consequência, mas, sim, transforma-se numa parte "essencial" da concentração, sendo que se trata de uma essência mediada historicamente pelo vício de consumo de tais choques. 
Desse modo, torna-se praticamente insuportável se concentrar por muito tempo na leitura de um determinado texto, pois o corpo e a mente como que imploram pelo acesso contínuo a novas informações audiovisuais, que precisam ser imediatamente consumidas por meio dos links que são constantemente trocados. E é exatamente essa troca constante que faz com que os usuários não consigam ter o tempo necessário para refletir de forma mais aprofundada sobre determinado tópico, o que poderia estimular a produção de representações mentais duradouras e, portanto, de novos conceitos. Eis a forma como a semiformação é revitalizada na sociedade da cultura digital, pois é nesta sociedade, na qual é possível lembrar-se de tudo por meio do acesso ininterrupto de quaisquer informações, que novas formas de esquecimento são engendradas.

No livro Delete: the virtue of forgetting in the Digital Age, Victor Mayer Schönberger (2009) cita dois casos que são paradigmáticos a respeito da relação entre a cultura digital, a semiformação e a memória. O primeiro caso, do ano de 2006, é o de uma aluna do Curso de Pedagogia de uma universidade dos Estados Unidos da América que estava prestes a se formar quando resolveu participar de uma festa de confraternização com outros alunos. Na festa, fantasiou-se de pirata, tirou um selfie e o postou na rede social MySpace com os dizeres: "pirata bêbada". Esta foto teve certa repercussão e foi vista por membros da direção da Faculdade de Pedagogia, os quais se reuniram e decidiram pela expulsão da aluna. A justificativa da expulsão foi a de que a imagem não era compatível com a imagem da faculdade, que ela não "condizia com a de uma futura pedagoga formada por aquela instituição" (SCHÖNBERGER, 2009, p. 01).

Já o outro caso, também ocorrido em 2006, refere-se à ocasião em que um psicólogo canadense de 60 anos de idade foi receber um amigo no Aeroporto Internacional Seatle-Tacoma, nos Estados Unidos da América, sendo este um procedimento comum e realizado várias vezes. Porém, certo dia, um funcionário da alfândega resolveu digitar o nome do psicólogo no mecanismo de busca de um provedor da internet e descobriu que ele havia sido detido em 1960 com uma pequena quantidade de LSD. Imediatamente, o psicólogo teve que assinar um documento no qual ele reconhecia ter sido detido numa apreensão policial que acontecera há 46 anos. Após ter assinado tal declaração, ele passou a ser impedido de entrar no país sob o risco de ser preso mediante a acusação de prática de tráfico de drogas (SCHÖNBERGER, 2009, p. 02).

Ambos os casos são paradigmáticos da forma como o pensamento estereotipado e o comportamento preconceituoso delirante, dois dos pilares da semiformação, são tecnologicamente renovados na cultura digital, ao mesmo tempo em que as mediações histórico-temporais são instrumentalmente manipuladas com o objetivo de 
reforçá-los. Nesse sentido, tanto a memória futura (primeiro caso) quanto a memória passada (segundo caso) se transformaram em novos presentes perpétuos, para fazer uso do conceito de Jameson (1985), nos tempos hodiernos, pois a estudante de Pedagogia e o psicólogo canadense foram condenados por meio do acesso a informações consubstanciadas a diferentes contextos e tempos distintos, mas que foram uniformizadas e perpetuamente eternizadas na forma de julgamentos fulminantes, ou seja, contínuos inescusáveis. Em ambos os casos, a conexão absoluta fomentou a exclusão absoluta. Mas novas formas de vigilância e exclusão já são anunciadas, pois o desenvolvimento tecnológico da internet que se avizinha parece ofertar a possibilidade de uma interface (GALLOWAY, 2012) entre humanos e objetos talvez apenas vislumbrada em obras de ficção científica: a chamada internet das coisas (Internet of things, IoT). Por meio da utilização da tecnologia de identificação por radiofrequência (RFID technology), objetos e mesmo pessoas podem ser etiquetados por meio de nanosensores na forma de chips capazes tanto de "interpretar" as informações quanto transmiti-las. Assim, os objetos e as pessoas que recebem as etiquetas RFID: “[...] são capazes de se comunicar com outros objetos devidamente etiquetados através da Internet ou de outros protocolos [...]. Tudo pode ser etiquetado para que possa participar da Internet das coisas" (ESPADA et al., 2011, p. 24). Certamente, o potencial de vigilância e controle, proveniente da aplicação desse tipo de tecnologia, ultrapassa o potencial das câmeras, uma vez que:

1) Os sensores estão se tornando cada vez menores, de tal modo que, com os avanços da nanotecnologia, não se sabe como e quando as informações de quaisquer pessoas estão sendo coletadas; 2) Consequentemente, bilhões de objetos do cotidiano podem ser equipados com tais sensores, fazendo com que novos tipos de dados sejam amealhados; e 3) Uma vez que os dados coletados façam parte de um sistema de rede globalizado, eles podem ser potencialmente agregados a outras informações pessoais registradas a qualquer momento (WINTER, 2014, p. 28).

Diante desse tipo de tecnologia, as sensações de paranoia e controle certamente encontrarão espaço para se propagar na sociedade do panóptico universal e atemporal. Porém, há o outro lado desta história, pois, ao serem etiquetados com tais chips, objetos e pessoas começam a participar de interfaces como esta: se um indivíduo que possui problemas cardíacos tem implantado este tipo de dispositivo eletrônico em seu corpo, os nanosensores podem "interpretar" os sinais fisiológicos indicadores do princípio de um infarto e enviá-los para o celular de um médico que usa o mesmo aparelho para avisar o paciente de que ele deve se dirigir imediatamente a um hospital. Uma vez que a própria tecnologia precisa ser compreendida não só como um conjunto de técnicas, mas principalmente como um processo social determinado pela intervenção humana, também o uso da tecnologia IoT possibilita fazer com que haja o desenvolvimento de experiências formativas emancipatórias, pois: 
[...] justamente a tecnologia da Internet das coisas, na condição de força produtiva humana, possibilita-nos acessar a história da hospedagem e da transformação das informações, a ponto de presencialmente nos religarmos com os espaços e tempos de nosso passado e, assim, projetarmos perspectivas de novos futuros (ZUIN; ZUIN, 2016).

No final do texto "Teoria da semiformação", Adorno constata a necessidade de se ter uma posição anacrônica em relação à possibilidade de permanência da Bildung: "agarrar-se com firmeza à formação depois que a sociedade já a privou de sua base" (ADORNO, 2010, p. 39). Porém, talvez a própria revitalização da formação não dependa atualmente de se aferrar a uma postura anacrônica, mas, sim, de compreender qual é sua atualidade diante das mediações históricas cujo caldo de cultura produz a ubiquidade dos celulares e, no limite, da internet das coisas.

Assim, não é possível pensar a permanência da Bildung atrelada exclusivamente à relação entre as forças produtivas e as relações de produção do final do século XVIII. A possibilidade de que permaneça na consciência o que ainda não existe depende também do modo como o acesso on-line de informações é feito, pois se pode reforçar não só o pensamento estereotipado e o comportamento preconceituoso delirante, como também o histórico de informações que, ao serem criticamente relacionadas entre si, convertem-se no substrato necessário para que tais vivências se transformem qualitativamente em experiências formativas. É verdade que a possibilidade de existência do indivíduo livre e radicado em sua própria consciência não pode ser obtida exclusivamente pela sua conexão com as transformações históricas proporcionadas pelo acesso inédito das informações via IoT, haja vista o fato de que atualmente, por exemplo, as relações de produção do capitalismo transnacional impingem a sintetização de drogas que eliminem definitivamente o próprio sono, justamente por ele ser considerado um momento improdutivo, que "desconecta" as pessoas (CRARY, 2015). Contudo, a crítica a tal estado de coisas, que pode, inclusive, estimular a revitalização do significado da Bildung, não pode ser apartada do uso desta mesma tecnologia que é, hoje em dia, majoritariamente utilizada para a reestruturação da semiformação.

\section{Conclusão}

Em 1932, Aldous Huxley descreveu, em seu Admirável mundo novo, a experiência do cinema sensível vivenciada pelo personagem selvagem. Ao ser como que "mergulhado em poltronas pneumáticas" (HUXLEY, 1969, p. 208) e ao apertar um botão de metal, o selvagem podia "sentir" seus lábios sendo pressionados e, portanto, o beijo praticado por atores em telas de altíssima definição. Já na sociedade do século XXI, pesquisadores de Cingapura acabam de anunciar a criação de 
uma limonada "virtual". Ao utilizar eletrodos para capturar o sabor da limonada, é possível reproduzi-lo num copo com outros eletrodos e que contém apenas água, de modo que quando alguém bebe a água sente o sabor da limonada. Segundo os pesquisadores, esta tecnologia já possibilita que as pessoas possam compartilhar sabores pela internet (REUTERS, 2017). Com esta tecnologia, a fruição dos choques audiovisuais atinge outro patamar fisiológico-estético, pois não só a visão e a audição são radicalmente transformadas, como também o paladar e, certamente, daqui a pouco tempo, o tato e o olfato, de forma coletiva.

Todas estas transformações do aparato sensório-motor também reverberam na forma como as pessoas desenvolvem as representações mentais derivadas de uma tecnologia que não mais parece representar a realidade, mas, sim, tornar-se a própria. É nesta sociedade da cultura digital que a própria capacidade de simbolização é canibalizada, não apenas por sensores, a ponto de os atuais consumidores de tais choques vivenciarem novas formas de dessublimação repressiva no século XXI.

Certamente, tudo isso tem um custo, pois também a capacidade de concentração, que é decisiva para a produção e a reprodução de representações mentais duradouras e, portanto, de conceitos, tende a se metamorfosear numa espécie de concentração dispersa, completamente afeita aos novos presentes perpétuos imperdoáveis do atual processo semiformativo. Os mesmos presentes que solapam as religações entre os tempos passado e futuro se ligam de tal maneira que as informações se eternizam e se tornam fetiches atemporais que preparam o terreno para que o pensamento estereotipado e o preconceito delirante vicejem cada vez mais. É na sociedade da concentração dispersa que se dissemina paulatinamente o diagnóstico do déficit de atenção entre as crianças que se tornam incapazes de focar a atenção em um determinado texto, mas que são como que hipnotizadas quando as telas dos gadgets eletrônicos, principalmente dos celulares, cintilam suas cores berrantes e capturam a atenção que será triturada logo em seguida por meio do fluxo constante de tais imagens e sons mesclados. Assim, o diagnóstico que lhes é imputado, ou seja, o de que são portadores do Transtorno de Déficit de Atenção com Hiperatividade (TDAH), dissimula o fato de que elas já vivem numa cultura do déficit de atenção, na qual "[...] a atividade cerebral de uma crescente quantidade de crianças e jovens deixou de corresponder a determinados padrões tradicionais de cultura" (TÜRCKE, 2016, p. 50).

$\mathrm{Na}$ sociedade de vício dos choques audiovisuais, que arrefece a capacidade de sublimação e, portanto, de simbolização, recrudesce-se, concomitantemente, o prazer sadonarcísico daquele que impõe seu ponto de vista como o único possível, tal como pode ser notoriamente observado nos "monodiálogos" estabelecidos, inclusive entre entes queridos nos grupos das redes sociais. Mas é nesta sociedade 
que a recuperação do histórico de informações, por meio da tecnologia IoT e do uso dos celulares, pode suscitar o desenvolvimento de novas formas de representações duradouras, de novos conceitos e simbolizações, de tal modo que a palavra diálogo, ou seja, uma relação a dois (ou mais), torne-se tecnologicamente renovada ao fomentar a presença de experiências formativas dos que, por meio de tais aparelhos, reapropriam-se criticamente dos nexos espaço-temporais que conferem as características identitárias do particular e do geral. Portanto, é justamente nesta sociedade que ainda ecoa a lembrança de Adorno, de que "[...] a única possibilidade de sobrevivência que resta à formação é a autorreflexão crítica sobre a semiformação em que necessariamente se converteu" (ADORNO, 1972, p. 121). Essa advertência, que também é uma esperança de renascimento da Bildung, faz-se cada vez mais necessária, sobretudo na cultura digital, na qual os novos Tântalos se aferram às ilusões tecnologicamente mais portentosas de que finalmente conseguiram alcançar o fruto ácido que lhes é digitalmente apresentado na atualidade.

\section{Referências}

ADORNO, Theodor. W. A indústria cultural. In: COHN, G. (Org.). Theodor W. Adorno: coleção grandes cientistas sociais. São Paulo: Ática, 1986. p. 92-99.

. Theorie der Halbbildung. In: Gesammelte Schriften 8-Soziologische Schriften 1. Frankfurt am Main: Suhrkamp Verlag, 1972. p. 93-121.

dez. 1996.

. Teoria da semicultura. Educação \& Sociedade, Campinas: Cedes, a. XVII, n. 56, p. 388-411,

. Teoria da semiformação. Tradução de Newton Ramos-de-Oliveira. In: PUCCI, Bruno; ZUIN, Antônio A. S.; LASTÓRIA, Luiz A. Calmon Nabuco (Org.). Teoria crítica e inconformismo: novas perspectivas de pesquisa. Campinas: Autores Associados, 2010. p. 7-40.

ADORNO, Theodor W.; HORKHEIMER, Max. Dialética do esclarecimento: fragmentos filosóficos. Tradução de Guido Antonio de Almeida. Rio de janeiro: Jorge Zahar, 1986.

CRARY, Jonathan. 24 /7: capitalismo tardio e os fins do sono. Tradução de Joaquim Toledo Jr. São Paulo: Cosac e Naify, 2015.

ESPADA, Pascual et al. Virtual objects on the Internet of things. Special Edition on Computer Science and Software Engineering, Spain, v. 1, n. 4, p. 23-29, 2011.

GALLOWAY, Alexander. The Interface effect. Cambridge: Polity, 2012.

GOGGIN, Gerard. Cell phone culture: mobile technology in everyday life. London; New York: Routledge - Taylor and Francis Group, 2007.

HORKHEIMER, Max; ADORNO, Theodor W. Kulturindustrie - Aufklärung als Massenbetrug. In: HORKHEIMER, Max; ADORNO. Gesammelte Schriften 3- Dialektik der Aufklärung. Frankfurt am Main: Suhrkamp Verlag, 1972. p. 146-204. 
HUXLEY, Aldous. Admirável mundo novo. Tradução de Felisberto Albuquerque. Rio de Janeiro: Cia. Brasileira de Divulgação do Livro, 1969.

JAMESON, Fredric. Pós-modernidade e sociedade de consumo. Novos Estudos Ebrap, São Paulo, v. 12 , n. 8 , p. 16-26, 1985 .

LASH, Scott; LURY, Celia. Cultural global industry. Cambridge: Polity, 2007.

PUCCI, Bruno. Educação a distância virtual e formação de professores no Brasil: considerações sobre as políticas educacionais a partir de 1996. In: PUCCI, Bruno; COSTA, Belarmino Cesar G. da; DURÃO, Fabio (Org.). Teoria crítica e crises: reflexões sobre cultura, estética e educação. Campinas, SP: Autores Associados, 2012. v. 1. p. 181-204.

REUTERS. Cientistas criam a limonada “virtual”. 2017. Disponível em: <http://link.estadao. com.br/noticias/inovacao,cientistas-criam-limonada-virtual,70001747438>. Acesso em: 27 abr. 2017.

SCHÖNBERGER, Victor Mayer. Delete: the virtue of forgetting in the Digital Age. Princeton: Princeton University Press, 2009.

TÜRCKE, Christoph. Erregte Gesellshaft: Philosophie der Sensation. München: C. H. Beck Verlag, 2002.

Hiperativos! Abaixo a cultura do déficit de atenção. Tradução de José Pedro Antunes. Rio de Janeiro: Paz e Terra, 2016.

. Sociedade excitada: filosofia da sensação. Tradução de Antônio Zuin, Fabio Durão, Francisco Fontanella e Mario Frungillo. Campinas: Editora Unicamp, 2010.

WINTER, Jenifer. Surveillance in ubiquitous network societies: normative conflicts related to the consumer in-store supermarket experience in the context of the Internet of things. Ethics Information Technology, Netherlands, v. 16, p. 27-41, 2014.

ZUIN, Vânia G.; BORGONOVE, Carolina M. Environmental education in distance learning in Environmental Engineering at Federal University of São Carlos, Brazil: potentialities and limitations towards a critical techno-scientific education. Brazilian Journal of Science and Technology, Germany, v. 3, p. 01-14, 2016.

ZUIN, Vânia G.; ZUIN, Antônio A. S. A formação no tempo e no espaço da Internet das coisas. Educação \& Sociedade, Campinas, v. 37, n. 136, p. 757-773, 2016.

A indústria cultural e a insustentabilidade dos rótulos verdes. In: ZUIN, Antônio A. S.; LASTÓRIA, Luiz A. Calmon Nabuco; GOMES, Luiz Roberto (Org.). Teoria crítica e formação cultural: aspectos filosóficos e políticos. Campinas: Autores Associados, 2012. p. 105-122. 